\title{
CRISE, CAPITAL FICTÍCIO E AFLUXO DE CAPITAIS ESTRANGEIROS NO BRASIL ${ }^{1}$
}

\author{
Rosa Maria Marques* \\ Paulo Nakatani*
}

\begin{abstract}
Este estudo tem como objetivo analisar o impacto sobre a economia brasileira do movimento de entrada de capitais ocorrido nos últimos anos, à luz do crescimento descomunal do capital fictício e do desenvolvimento da crise econômica mundial. Além de chamar atenção para o volume de recursos envolvidos e seu impacto sobre o nível das reservas e a taxa de câmbio, salienta a importância daqueles registrados na conta capital e financeira do balanço de pagamentos como investimento em carteira e derivativos, o que configura um grau elevado de exposição da economia aos movimentos bruscos do capital internacional, principalmente na hipótese de um recrudescimento da crise. $\mathrm{O}$ artigo traz, ainda, elementos sobre a origem e o destino dos investimentos diretos realizados no país com capital estrangeiro, bem como sua importância nos processos de privatização, fusão e aquisição.

Palavras-CHAVE: Crise. Capital fictício. Capital estrangeiro. Desnacionalização. Brasil.
\end{abstract}

A partir dos anos 1980, com a desregulamentação monetária e financeira, a descompartimentalização dos mercados financeiros nacionais e a desintermediação bancária promovidas pelos principais Estados capitalistas, especialmente os Estados Unidos e a Inglaterra, assistiu-se ao denvolvimento crescente de formas fíctícias do capital, cuja expressão mais conhecida pelos leigos são os derivativos. Esse crescimento do capital fictício, de um lado, mostrava a incapacidade de o capitalismo resolver suas contradições, provocadas pelo esgotamento, em meados dos anos 1970, do ciclo expansivo do pós-guerra, pois não conseguia manter as mesmas condições de reprodução do capital assentadas em taxas crescen-

* Doutora em Ciências Econômicas. Professora titular do Departamento de Economia e do Programa pós-graduado em Economia Política da Pontifícia Universidade Católica de São Paulo.

Rua Monte Alegre, 984 - $1^{\circ}$ andar - sala 122-A. Perdizes - São Paulo-SP-Brasil.Cep: 05014-901.rosamkmarques@gmail.com

** Doutor em Ciências Econômicas. Professor do Departamento de Economia e do Programa de Pós-Graduação em Política Social da Universidade Federal do Espírito Santo.paulonakatani@gmail.com

${ }^{1}$ Este artigo é uma versão modificada daquele que foi apresentado no seminário da Red de Estudios de la Economía Mundial (Redem) 2012 "Desarrollo y crisis en el Capitalismo”, em São Paulo. tes de lucro do período dos trinta anos gloriosos; de outro, ao se constituir em uma fuga para frente, aprofundou as contradições do capitalismo, o que se manifestou em sucessivas crises financeiras, todas elas ocorridas antes daquela de 2007 / 2008, iniciada no coração do capitalismo contemporâneo, isto é, nos Estados Unidos.

A liquidez decorrente da expansão do capital fictício e a busca por melhores condições de reprodução do capital em geral levaram ao aumento do fluxo internacional de capitais para as economias onde essas condições eram mais favoráveis, com destaque para a taxa de exploração da força de trabalho elevada.

O Brasil entrou tardiamente no processo de liberalização dos fluxos de capital e mercadorias no período neoliberal, se o comparamos a outros países do mundo. Entretanto, a relação entre os capitais brasileiros e aqueles do centro do sistema mundial não sofreu nenhuma mudança substantiva em seus fundamentos: além do aumento da desnacionalização da economia, os capitais estrangeiros continuam a ser fonte de expressivas remessas de excedente para o exterior e tornaram a 
economia brasileira ainda mais exposta ao movimento do capital internacional, principalmente em momentos de crise.

Qual o impacto da inserção da economia brasileira no movimento do capital internacional no período recente? Para responder a essa indagação, na primeira parte deste estudo, é analisada a evolução do capital portador de juros no mundo especialmente do capital fictício - no período pós 2008, a fim de explicitar o contexto em que ocorreu o aprofundamento da "internacionalização" da economia brasileira mediante o aumento do afluxo de capitais estrangeiros na conta capital e financeira do balanço de pagamentos. Na segunda parte, é tratado o processo de intensificação da presença do capital estrangeiro no país, a partir do acompanhamento do crescimento significativo do afluxo de capitais estrangeiros diretos em carteira (Bolsa) e em derivativos. Nessa parte, também é destacada a origem e o destino dos investimentos diretos realizados no país com capital estrangeiro, bem como sua importância nos processos de privatização, fusão e aquisição.

\section{ACRISEEOCAPITALFICTÍCIO INTERNACIONAL}

Quatro anos após a crise do capitalismo, que se manifestou na esfera financeira nos EUA em 2008, ela continua se aprofundando em parte dos países da área do Euro e com reflexos por todo o mundo. A taxa mundial de crescimento do PIB, que já era baixa, tende a cair ainda mais no futuro próximo, segundo as previsões do Fundo Monetário Internacional (FMI), e pelas expectativas pessimistas dos capitalistas, segundo muitos economistas. A economia mundial cresceu 1,33\% em 2008, -2,25\% em 2009, 4,34\% em 2010 e 2,71\% em 2011. Nos Estados Unidos (EUA), após a retração de 2008 e 2009, com taxas de crescimento do PIB de -0,36\% e -3,53\% respectivamente, a ligeira recuperação de 2010 (3,02\%) foi seguida de nova retração em 2011, com uma taxa de crescimento de apenas 1,70\% (Banco Mundial, 2012). O desempenho na área do Euro foi pior nesses anos, em particular em alguns países como a Grécia, Portugal, Espanha, Itália e Irlanda. Nem todos os países apresentaram esse mesmo comportamento nesses anos, como foi o caso da China ou dos BRICS. Mas a esperança de que a China e os demais países dos BRICS possam garantir uma taxa de crescimento mais elevada do PIB e alavancar o crescimento da acumulação mundial já está sendo progressivamente abandonada.

Desde fins de 2008, na tentativa de estimular o investimento e o consumo, a política monetária dos principais bancos centrais do mundo, como o Federal Reserve, o Banco Central Europeu, o Banco da Inglaterra, o Banco Central do Japão, tem sido a de reduzir, continuamente, a taxa básica de juros. Esses bancos centrais não só têm reduzido as taxas de juros como têm, ao mesmo tempo, efetuado criação primária de moeda e monetizado dívidas, ${ }^{2}$ expandindo a base monetária, sem nenhuma preocupação quantitativista a respeito dos preços. Esses países já atingiram os limites em que as taxas reais de juros começam a se tornar negativas, sem que os investimentos nem a demanda tenham voltado a crescer significativamente. Seguindo essa tendência, o Brasil e a China também continuam reduzindo suas taxas básicas de juros. Essa política monetária, de corte nitidamente keynesiano, ${ }^{3}$ não só não tem produzido

O Federal Reserve duplicou a base monetária entre 2007 e 2008, aumentou em $22 \%$ e $30 \%$ em 2009 e 2011, respectivamente; apenas em 2010 houve uma redução de $0,4 \%$. No total, entre dezembro de 2007 e de 2011, o aumento foi de $68,4 \%$ (FED, 2012). Quanto ao Banco Central Europeu, entre dezembro de 2011 e fevereiro de 2012, ele expandiu a base monetária em um trilhão de euros através das Operações de Refinanciamento de Longo Prazo (CITYWIRE, 2012), sem que isso produzisse um efeito significativo no M1. Assim, a criação primária de moeda foi diretamente para o M2 ou M3 espalhando-se por outros mercados. ${ }^{3}$ Durante a grande depressão dos anos 1930, o nível de acumulação do capital, nos países centrais do capitalismo ocidental, chegou a certos patamares que começou a exigir estímulos ou incentivos estatais para serem acumulados. Assim, a ideia de Marx sobre a tendência inexorável à acumulação começou a ser questionada na realidade. Naquela época, a crise destruiu uma enorme massa de capital, mas que não foi suficiente para a plena retomada da acumulação. Somente a II Grande Guerra concluiu essa desvalorização. Naquele período, Keynes escreveu que "a longo prazo, o capital deve conservar-se suficientemente escasso para que a sua eficiência marginal do capital seja pelo menos igual à taxa de juros correspondentes à duração de sua existência" (Keynes, 1985, p.153). Essa foi uma das razões pela qua Keynes defendia a ideia de que o Estado, em sua política 
os efeitos desejados de retomada dos investimentos e do emprego, quanto continua levando a uma queda ainda maior da produção e do emprego em alguns países da área do Euro. Em parte, isso decorre da expansão da esfera financeira e dos capitais fictícios nos mercados internacionais e, em parte, pelo movimento do capital dinheiro para países com taxas mais elevadas de juros e de lucros.

Já a política fiscal ${ }^{4}$ nos países que mais estão sofrendo os impactos da crise é nitidamente oposta à concepção keynesiana de estímulos à demanda agregada, pois está direcionada à redução dos déficits fiscais através da diminuição dos salários, cortes de gastos públicos e redução de benefícios previdenciários, entre outras medidas, que afetam, profundamente, o poder de compra dos trabalhadores. Mas nem todos os países têm seguido essa receita ortodoxa, como é o caso do Brasil. Até o momento, nem a política monetária e nem as diferentes políticas fiscais estão conseguindo mudar o quadro de estagnação geral, levando os analistas de bancos, empresas e governos a adiar, por mais um ano, a esperada retomada do crescimento.

A superacumulação de capital, que se manifestou desde os anos 1970 e levou a movimentos cíclicos de expansão e crise, ampliou a acumulação na esfera financeira e a geração de capital fictício, como já tratamos em outro texto (Marques e Nakatani, 2009). Nos últimos anos, a ação estatal tem reduzido a destruição do excesso de capital nessa esfera, assim como na produtiva. Assim, o capital fictício, na forma da dívida pública, não só não foi desvalorizado, como cresceu, significativa-

monetária, deveria reduzir a taxa de juros para desestimular uma propensão ou tendência a entesourar, e fazer com que a taxa de juros caísse mais rapidamente do que a eficiência marginal do capital, estimulando os investimentos produtivos. Essa é, também, a situação em que o capital se encontra atualmente nos países em que os estímulos monetários ou fiscais não estão proporcionando uma taxa mais elevada de crescimento da produção.

${ }^{4}$ A rigor, parece que a ortodoxia econômica presente nas instituições multilaterais, como FMI e Banco Mundial, assim como na direção econômicas dos diferentes países, não tem nenhuma ação coerente frente à crise, na qual o BCE tende a tomar medidas keynesianas em termos da política monetária e os governos dos Estados nacionais estão sendo obrigados a tomar medidas ortodoxas, opostas à política monetária, de redução dos déficits fiscais. mente, nos anos após o colapso do Lehman Brothers, no mundo e em quase todos os países. ${ }^{5}$

Os dados disponíveis no BIS - Banco de Compensações Internacionais - mostram que o endividamento interno dos governos tem crescido exponencialmente, tendo quase dobrado entre dezembro de 2005 e junho de 2011 (Tabela 1). Esse crescimento trouxe como consequência uma pesada carga de juros e crises da dívida para vários países europeus. Os países que adotaram a política de metas de inflação costumam fixar taxas elevadas de juros para pagarem os credores dessas dívidas, inclusive como meio de atrair divisas, que irão compor suas reservas, que poderiam servir como meio de enfrentar ataques especulativos em momentos de crise mais aguda. Ao ingressarem na área do euro, os países decidiram renunciar à sua soberania monetária, abandonando o papel que os bancos centrais desempenham como banqueiros do governo, assim, o financiamento dos déficits fiscais nominais depende das decisões dos bancos privados. Ou seja, o Banco Central Europeu compra títulos dos bancos privados mediante emissão moeda e estes bancos, então, podem comprar os títulos da dívida dos países da área do euro às taxas que eles determinam no mercado.

As estimativas da dívida pública, em termos de porcentagem do PIB, ${ }^{6}$ variam bastante de país para país e, também, dentre os governos dos países em crise na área do Euro, os PIGS, que não são, necessariamente, os mais endividados. Essa dívida está distribuída nos ativos dos bancos,

${ }^{5}$ Como sabido, os capitais que não conseguem continuar acumulando acabam perdendo espaço, são centralizados ou vão à falência, ou seja, a natureza mesma do capital exige um processo contínuo de acumulação, segundo Marx. Esse processo de acumulação conduz, periodicamente, às crises de superacumulação de capital, que se manifestam quando se esgotam os mecanismos e os efeitos dos fatores que contrariam a tendência à queda na taxa de lucros, ao contrário da ideia de que sejam causadas por expectativas pessimistas, ganância exagerada, incompetência ou erros de política econômica. Além disso, é o momento em que o capital se livra de suas escórias, daquelas unidades menos produtivas que devem ser desvalorizadas. Assim, as crises periódicas têm um papel muito importante na dinâmica do capital, devem desvalorizar ou destruir todas aquelas unidades que foram superadas pelo desenvolvimento técnico e social das forças produtivas. Entretanto, a política econômica aplicada pelos Estados nacionais tem evitado, continuamente, que o potencial de regeneração do capital, desempenhado pela crise, seja plenamente realizado.

${ }^{6}$ Ver Gontijo, 2012, p. 19. 
Tabela 1 - Títulos de dívida interna de governos selecionados (US\$ bilhões)

\begin{tabular}{lrrrrrrr}
\hline Países Selecionados & $\mathbf{2 0 0 5}$ & $\mathbf{2 0 0 6}$ & $\mathbf{2 0 0 7}$ & $\mathbf{2 0 0 8}$ & $\mathbf{2 0 0 9}$ & $\mathbf{2 0 1 0}$ & 2011* $^{*}$ \\
\hline Todos os governos & 22.165 & 24.152 & 26.772 & 29.441 & 34.018 & 38.887 & 41.059 \\
\hline Alemanha & 1.072 & 1.223 & 1.393 & 1.364 & 1.548 & 1.725 & 1.919 \\
\hline Brasil & 419 & 512 & 694 & 546 & 804 & 949 & 957 \\
\hline Espanha & 407 & 449 & 496 & 449 & 604 & 629 & 737 \\
\hline EUA & 5.918 & 6.230 & 6.593 & 7.895 & 9.472 & 11.154 & 11.606 \\
\hline França & 1.080 & 1.209 & 1.405 & 1.437 & 1.693 & 1.662 & 1.941 \\
\hline Grécia & 207 & 244 & 299 & 182 & 181 & 159 & 172 \\
\hline Itália & 1.324 & 1.539 & 1.772 & 1.780 & 1.973 & 1.934 & 2.174 \\
\hline Portugal & 98 & 109 & 124 & 87 & 99 & 115 & 137 \\
\hline Reino Unido & 680 & 835 & 903 & 826 & 1.189 & 1.326 & 1.382 \\
\hline
\end{tabular}

Fonte: BIS. Quarterly review. Tabela 16A, vários números.

* em junho 2011

dos fundos de pensão e previdência, dos fundos de investimento, das empresas e das pessoas físicas. No caso dos títulos dos Estados Unidos, esses títulos da dívida interna podem estar, também, nas reservas internacionais dos países.

Outro componente do capital fictício, que é representado pelo valor de mercado ou valor acionário, e é estimado pela multiplicação do número de ações de cada empresa pela cotação dessa ação, sofreu uma redução após 2007, mas não tão importante quanto deveria. Em termos mundiais, o valor acionário, que tinha chegado a US\$ 64,5 trilhões em 2007, caiu para US $\$ 34,90$ trilhões, em 2008, uma redução de 46,0\%. Na área do Euro e na União Europeia, a queda foi maior, de $50,8 \%$ e $51,5 \%$ respectivamente (Tabe- sofreram uma recuperação por toda a parte, mas sofreu nova queda em 2011. A recuperação foi, em grande parte, fruto das políticas de salvamento dos bancos nos Estados Unidos, Reino Unido e Europa, em que os governos lançaram mão de emissão de moeda e monetização de títulos da dívida para comprar títulos desvalorizados (derivativos tóxicos) ou ações dos ativos bancários.

Considerando os principais países capitalistas ocidentais, o comportamento do mercado acionário foi muito parecido: entre 2007 e 2008, a queda foi de $41,2 \%$ nos Estados Unidos, de 52,0\% no Reino Unido, de 47,4\% na Alemanha e de $46,1 \%$ na França. Todos esses países recuperaram uma parte importante do capital fictício nos dois anos seguintes, mas sofreram igualmente quedas em 2011. Esse capital fictício, es-

lsas de valores (US\$ bilhões)

Tabela 2 - Valor de mercado das empresas cotadas nas bolsas de valores (US\$ bilhoes)

\begin{tabular}{lrrrrrrrr}
\hline Discriminação & $\mathbf{2 0 0 5}$ & $\mathbf{2 0 0 6}$ & $\mathbf{2 0 0 7}$ & $\mathbf{2 0 0 8}$ & $\mathbf{2 0 0 9}$ & $\mathbf{2 0 1 0}$ & $\mathbf{2 0 1 1 *}$ \\
\hline Área do Euro & 6.357 & 8.651 & 10.475 & 5.155 & 6.148 & 6.277 & 5.483 \\
\hline União Européia & 10.199 & 13.545 & 15.632 & 7.582 & 9.823 & 10.504 & 7.565 \\
\hline Mundo & 43.319 & 53.375 & 64.575 & 34.901 & 47.380 & 54.511 & 45.083 \\
\hline Alemanha & 1.221 & 1.638 & 2.106 & 1.108 & 1.298 & 1.430 & 1.184 \\
\hline Brasil & 475 & 711 & 1.370 & 589 & 1.167 & 1.546 & 1.229 \\
\hline Espanha & 960 & 1.323 & 1.800 & 946 & 1.297 & 1.172 & 1.031 \\
\hline EUA & 16.971 & 19.426 & 19.947 & 11.738 & 15.077 & 17.139 & 15.641 \\
\hline França & 1.759 & 2.429 & 2.771 & 1.492 & 1.972 & 1.926 & 1.569 \\
\hline Grécia & 145 & 208 & 265 & 90 & 55 & 73 & 34 \\
\hline Itália & 798 & 1.027 & 1.073 & 521 & 317 & 318 & 431 \\
\hline Portugal & 67 & 104 & 132 & 69 & 99 & 82 \\
\hline Reino Unido & 3.058 & 3.794 & 3.859 & 1.852 & 2.796 & 3.107 & 1.202 \\
\hline
\end{tabular}

Fonte: World Bank. http://data.worldbank.org/indicator/CM.MKT.LCAP.CD/countries?Display= default. 
timado em relação ao PIB, chegou a 181,9\% no mundo e $305,2 \%$ nos Estados Unidos, no auge da expansão financeira em 2007, e fechou 2011 com $98,0 \%$ e $203,7 \%$ do PIB, respectivamente.

As modificações do capital fictício na forma do capital bancário ${ }^{7}$ e de outras instituições financeiras podem ser observadas na Tabela 3. Os ativos totais dos bancos, que vinham crescendo, sofrem uma pequena queda de $4,7 \%$ entre 2007 e 2008, continuam caindo em 2009 e 2010 e voltam a crescer em 2011. Mas são modificações pequenas que não alteraram, significativamente, o quadro, como o crescimento observado entre 2005 e 2007, de 56,8\%. Pode-se ver, ainda, nesta Tabela, que a maior parte dos ativos é externa, indicando que se trata de grandes corporações bancárias desses 40 países, com operações por todo o mundo. Cumpre destacar que uma parte dos ativos das instituições não bancárias constitui, também, capital fictício, pois aí estão incluídas as instituições financeiras não bancárias, que podem ser fundos de pensão ou fundos de investimentos das mais variadas formas.

A parte mais espetacular do crescimento de capital fictício apareceu na forma de novos instrumentos financeiros, cada vez mais complexos, chamados de derivativos. Esse mercado, junto com as bolsas de valores, são essencialmente de apostas sobre preços futuros de tudo o que se possa imaginar.

Mas alguns produtos, como taxas de juros e moedas, destacam-se pelo volume de negócios em termos internacionais. Este volume é medido por um valor "nocional", pois representa os contratos sobre o montante total apostado, que pode ser revertido, se for uma opção, ou, no final, são pagas apenas as diferenças entre o preço apostado e o preço verificado. Esse mercado, que foi conhecido como o Cassino global, acabou tornando-se um refúgio para a riqueza acumulada na forma financeira, no qual os ganhos e perdas constituem, em sua maioria, transferência de riqueza acumulada anteriormente. Isso não exclui que uma parte das remunerações obtidas nesse mercado não seja extraída da mais-valia gerada na produção de valor.

O mercado de moedas, mesmo estando em segundo lugar no saldo dos derivativos de câmbio (Tabela 4), é um dos mais ativos e não sofreu, significativamente, o impacto da crise iniciada em 2007. Segundo um levantamento que o BIS efetua a cada três anos, o volume de negócios diários no mercado de derivativos de moedas cresceu de forma impressionante nos últi-

Tabela 3 - Ativos financeiros totais (US\$ bilhões)

\begin{tabular}{lrrrrrrr}
\hline Discriminação & $\mathbf{2 0 0 5}$ & $\mathbf{2 0 0 6}$ & $\mathbf{2 0 0 7}$ & $\mathbf{2 0 0 8}$ & $\mathbf{2 0 0 9}$ & $\mathbf{2 0 1 0}$ & $\mathbf{2 0 1 1}$ \\
\hline Ativos Totais & 23.911 & 29.468 & 37.439 & 35.266 & 33.838 & 33.971 & 35.604 \\
\hline Bancos & 14.886 & 18.227 & 23.340 & 22.252 & 21.085 & 20.965 & 21.760 \\
\hline Outras instituições não bancárias & 9.025 & 11.241 & 14.099 & 13.013 & 12.754 & 13.007 & 13.844 \\
\hline Ativos Externos & 21.125 & 26.182 & 33.494 & 31.193 & 30.079 & 30.170 & 31.567 \\
\hline Bancos & 13.385 & 16.546 & 21.472 & 20.266 & 19.251 & 19.141 & 19.786 \\
\hline Outras instituições não bancárias & 7.740 & 9.636 & 12.022 & 10.928 & 10.828 & 11.028 & 11.781 \\
\hline Ativos locais em moeda estrangeira & 2.786 & 3.288 & 3.945 & 4.072 & 3.760 & 3.802 & 4.038 \\
\hline Bancos & 1.501 & 1.682 & 1.868 & 1.987 & 1.834 & 1.823 & 1.974 \\
\hline Outras instituições não bancárias & 1.285 & 1.606 & 2.077 & 2.086 & 1.926 & 1.978 & 2.064 \\
\hline
\end{tabular}

Fonte: BIS. Quarterly review. Vários números.

* Junho de 2011

7 "A maior parte do capital bancário é, portanto, puramente fictícia e consiste em títulos de dívidas (letras de câmbio), títulos de dívida pública (que representam capital passado) e ações (direitos sobre rendimento futuro). [...] Além disso, esse capital fictício do banqueiro, em grande parte, não representa seu próprio capital, mas o do público, que o deposita com ele, com ou sem juros.” (Marx, 1986, p.13).

mos anos. Em 1998, o total de negócios foi de US\$ 1,5 trilhão por dia, tendo chegado a US $\$ 1,9$ trilhão em 2004 e a US\$ 3,3 trilhões em 2007, no início da crise. Em 2010, depois dos impactos da crise 
por todo o mundo, o volume de negócios no mercado de derivativos de moeda, ou de câmbio, chegou a US\$ 3,981 trilhões por dia, ano em que o PIB mundial foi estimado em cerca de US\$ 63 trilhões (BIS, 2010, p.7). Em termos de moedas, os contratos em dólar representavam $88,0 \%{ }^{8} \mathrm{em}$ 2004, caíram para $85,6 \%$ em 2007 , e para $84,9 \%$ em 2010; o euro está colocado em segundo lugar, com $37,4 \%, 37,0 \%$ e $39,1 \%$; o yen japonês com $20,8 \%, 17,2 \%$ e $19,0 \%$, respectivamente, nos mesmos anos (BIS, 2010, p.12). Isso significa que o peso relativo das principais moedas praticamente não se alterou e o dólar ainda permanece como a principal moeda de reserva e negócios internacionais.

A Tabela 4 mostra o ponto a que chegou o que Marx chamou de alienação na forma capital portador de juros. O montante total dos derivativos no conceito OTC - Over The Counter -, também chamado de operações de balcão nos mercados financeiros, atingiu 647,7 trilhões de dólares, cerca de dez vezes o PIB mundial de 2011. Observando os dados do BIS na Tabela 4, a chamada crise de 2008 não teve repercussão significativa nesse mercado de derivativos. Ou seja, a superacumulação de capital, que foi direcionada para a esfera financeira, continua a comandar o sistema financeiro internacional, especulativo e parasitário, extraindo excedentes dos países atrasados ou emergentes, na forma de remessas de lucros, pagamento de juros e de royalties.

Esses dados mostram que o impacto da

Tabela 4 - Saldos de Derivativos OTC - valor nocional em US\$ bilhões

Fonte: BIS. Quarterly review. Vários números

O total relativo não é de $100 \%$, mas de $200 \%$, pois esses contratos envolvem duas moedas, conforme explica o BIS na tabela respectiva.

crise e das políticas anticrise dos países centrais não se restringiram ao seu próprio território. A política de criação monetária para salvar os bancos e resgatar o valor fictício dos títulos tóxicos transferiu para as outras economias parte dos custos da crise e da desvalorização do capital. Por exemplo, a desvalorização do dólar faz com que todos os países que mantêm as suas reservas em dólares percam o respectivo montante.

Considerando o desempenho das economias centrais no período pós 2008, parte do capital internacional (sob todas as formas) tem se direcionado para os BRICs ou para outras economias periféricas. Os reflexos desse movimento no Brasil são objeto da segunda parte desse artigo. Dada a não resolução da crise mundial e a contínua expansão do capital portador de juros, especialmente de sua forma fictícia, esse redirecionamento resulta em aumento da exposição do país aos movimentos bruscos desse capital, com graves consequências para o país.

\section{A INTENSIFICAÇÃO DA PRESENÇA DO CAPITAL ESTRANGEIRO NO PAÍS}

No Brasil, a presença do capital estrangeiro sempre foi marcante, principalmente por sua inserção na atividade industrial. Essa presença foi fruto da opção havida nos anos 1950 de promover o processo de substituição de importação mediante o tripé formado pelo Estado e o capi-

\begin{tabular}{lrrrrrrr}
\hline Discriminação & $\mathbf{2 0 0 5}$ & $\mathbf{2 0 0 6}$ & $\mathbf{2 0 0 7}$ & \multicolumn{1}{c}{$\mathbf{2 0 0 8}$} & \multicolumn{2}{c}{$\mathbf{2 0 0 9}$} & \multicolumn{2}{c}{$\mathbf{2 0 1 0}$} & 2011* \\
\hline Cambio & 31.364 & 40.271 & 56.238 & 49.753 & 49.181 & 57.796 & 63.349 \\
\hline Taxa de Juros & 211.970 & 291.582 & 393.138 & 418.678 & 449.875 & 465.260 & 504.098 \\
\hline Commodities & 5.434 & 7.115 & 8.455 & 4.427 & 2.944 & 2.922 & 3.091 \\
\hline CDS & 13.908 & 28.650 & 57.894 & 41.868 & 32.693 & 29.898 & 28.633 \\
\hline Outros & 34.994 & 47.228 & 79.616 & 77.237 & 69.207 & 45.170 & 48.591 \\
\hline Total & 297.670 & 414.845 & 595.341 & 591.963 & 603.900 & 601.046 & 647.762 \\
\hline
\end{tabular}

tal nacional e estrangeiro, que continuou nas décadas seguintes. A partir do início dos anos 1990, no governo Collor, uma série de medidas irá defi- 
nir uma nova inserção da economia brasileira no mercado internacional e promover a intensificação da presença do capital estrangeiro no país, tanto nas atividades produtivas quanto na esfera financeira. Além do processo de desestatização, deflagrado com a criação do Plano Nacional de Desestatização (PND), que resultou na privatização de empresas anteriormente consideradas estratégicas para o desenvolvimento da nação, foi promovida a abertura comercial e financeira ao resto do mundo.

\section{As privatizações e o investimento estrangeiro direto}

O processo de privatização pode ser dividido em dois períodos: 1990-1994; 1995-2002. ${ }^{9}$ No primeiro, que compreende os governos Collor e Itamar, foram privatizadas 33 empresas, com destaque para o setor siderúrgico (64\%) e petroquímico (22\%), resultando em US\$ 11.874 milhões (produto da receita da venda e da dívida transferida). No segundo período, passaram para o setor privado 35 empresas, entre as quais a Companhia Vale do Rio Doce, ${ }^{10}$ resultando em US\$ 93.424 milhões. É neste segundo período que, além dos setores já afetados, foram incluídos o elétrico, o financeiro e as concessões das áreas de transporte, rodovias, saneamentos, portos e telecomunicações. Nesta segunda fase, as empresas afetadas eram de infraestrutura / serviços $(80 \%$ - elétrico, telecomunicações, transporte, portuário, financeiro, gás e saneamento e informática), da indústria (14\% - petroquímica, petróleo e mineração), sendo $6 \%$ de empresas de vários setores de atividade, onde o Estado detinha participação minoritária. Em relação ao setor

${ }^{9}$ Durante o governo Lula, as privatizações não pararam, embora tenham sido marginais frente ao volume privatizado anteriormente. Entre outras, as privatizações foram de rodovias federais (saindo vitorioso nos leilões de concessão o grupo espanhol OHL), da Ferrovia Norte - Sul (concedida à Vale, antiga Companhia Vale do Rio Doce), bancos, hidrelétricas e linhas de transmissão.

${ }^{10}$ A Companhia Vale do Rio Doce, uma das maiores produtoras e exportadoras de minério de ferro do mundo, foi privatizada em maio de 1997. do petróleo, embora a Petrobrás (Petróleo Brasileiro S.A) ainda seja considerada uma empresa estatal, em 2000, foi vendida uma quantidade de ações ordinárias no mercado nacional que excedia o mínimo necessário à manutenção do controle acionário pelo Estado e, em 2001, ações preferenciais nominativas no mercado internacional.

Até 1994, a presença do investidor estrangeiro na privatização foi bastante pequena, não superando $5 \%$ do total da receita derivada da venda das empresas. No segundo período, no entanto, essa participação subiu para 53\%. Essa maior presença do capital estrangeiro no processo de privatização manifestou-se no aumento do fluxo do investimento estrangeiro direto (IED) na conta capital e financeira do balanço de pagamentos.

No período 1994 a 2011, o fluxo de IED líquido ${ }^{11}$ no país elevou-se de US\$ 2.150 milhões para US\$ 66.660 milhões. No Gráfico 1, vê-se claramente que há dois períodos de forte expansão do IED líquido: na segunda fase da privatização e a partir de 2007, com destaque para os dois últimos anos da série, isto é, quando é deflagrada a crise no capitalismo central. Nos últimos anos, com exceção do ocorrido em 2009, o aumento do fluxo do IED líquido no país foi resultado do movimento internacional dos fluxos de IED, quando o volume relativo destinado aos países em desenvolvimento (ou da periferia) aumentou, dado o aumento da incerteza nos países centrais, provocada pela continuidade e pelo aprofundamento da crise. Em 2011, o Brasil foi o quinto país de destino do IED no mundo, somente perdendo para os Estados Unidos, China, Bélgica e Hong Kong. Do total do IED no mundo, o país recebeu 4,4\% nesse ano, frente a 1,7\% em 2006 (UNTCTAD, 2012). Em relação à distribuição do fluxo do IED líquido entre investimento - participação no capital e empréstimo intercompanhia, observa-se um aumento na participação dos empréstimos nos últimos anos, motivada pelo spread entre a taxa de juros interna e a externa, principalmente a estadunidense.

\footnotetext{
${ }^{11}$ O IED líquido exclui as saídas de investimento estrangeiro em participação no capital e os débitos relativos a em-
} préstimos intercompanhias. 
Gráfico 1 - Investimento Estrangeiro Direto Líquido - 1995 a 2011 (US\$ milhões)

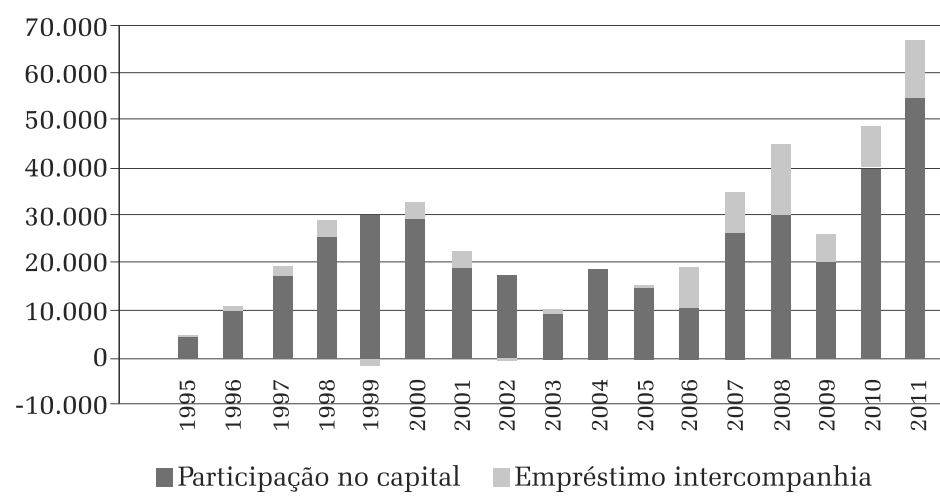

Fonte: BACEN. Elaboração própria.

O desempenho das entradas e saídas do IED traduz, de forma ampliada, a tendência do fluxo do IED líquido, com acentuado crescimento da entrada na segunda fase do processo de privatização e nos dois últimos anos. A queda observada em 2009 reflete a paralisia da economia, quando o PIB se retraiu em $0,2 \%$ e o país deixou, momentaneamente, de ser atrativo para o investimento estrangeiro direto (Gráfico 2).

Gráfico 2 - Investimento Estrangeiro Direto 1995 a 2011 (US\$ milhões)

\section{O estoque do investimento estrangeiro no Brasil}

O fluxo de IED líquido resultou num estoque total de IED, em 31 de dezembro de 2010, de US $\$ 660,5$ bilhões, o equivalente a $30,8 \%$ do PIB (BACEN, 2011). Esse montante guarda uma diferença em relação ao valor anteriormente estimado pela Posição Internacional de Investimentos (PII), realizado, também, pelo Banco Central, de US\$ 188 bilhões, pois considera o valor de mercado e não o valor histórico como a PII. Em relação ao estoque de IED de 1995 (de US\$ 41,4 milhões), o estoque aumentou quase 16 vezes (BACEN, 1996). Como mencionado anteriormente, o primeiro grande impulso para essa maior presença do capital estrangeiro no país foi devido à privatização promovida na economia brasileira a partir de 1990.

Em 2010, o estoque de IED - participação no capital - atingiu US\$ 579,6 bilhões (27\% do PIB e 53,6\% superior ao valor estimado pela PII). Em relação ao ano de 2005, o crescimento foi de 256\%. Já os estoques de IED - empréstimos intercompanhia - atingiram US\$ 80,9 bilhões, $15 \%$ inferior ao estimado pela PII, por não incluir os empréstimos de filiais de empresas brasileiras no exterior às suas matrizes no país.

Considerando o estoque de IED por país do investidor, os Países Baixos são responsáveis por $28,1 \%$ do estoque total por participação no capital e por $8,4 \%$ dos empréstimos intercompanhias $(25,7 \%$ do tal do IED). Seguem os Estados Unidos (19\%, $18,6 \%$ e $19,0 \%$, respectivamente) e a Espanha $(12,2 \%, 11 \%$ e $12 \%$, respectivamente) (Tabela 5).

A distribuição do IED - participação no capital - se altera, significativamente, quando se considera o critério de investidor final - que reclassifica o país de origem do investimento, levando em consideração a cadeia de controle da empresa não residente, e que permite conhecer a origem primária dos recursos investidos, minimizando a distorção que a canalização de investimentos por paraísos fiscais e 
Tabela 5 - IED no País, por país do investidor imediato - estoque em 31/12/2010

\begin{tabular}{|c|c|c|c|c|c|c|}
\hline \multirow[t]{2}{*}{ Países } & \multicolumn{2}{|c|}{$\begin{array}{c}\text { Participação no } \\
\text { capital }\end{array}$} & \multicolumn{2}{|c|}{$\begin{array}{c}\text { Empréstimos } \\
\text { intercompanhias }\end{array}$} & \multicolumn{2}{|l|}{ Total } \\
\hline & US\$ milhões & $\%$ & US\$ milhões & $\%$ & US\$ milhões & $\%$ \\
\hline Total & 579.627 & 100,00 & 80.881 & 100,00 & 660.507 & 100,00 \\
\hline Países Baixos (Holanda) & 162.740 & 28,08 & 6.765 & 8,36 & 169.505 & 25,66 \\
\hline Estados Unidos & 110.356 & 19,04 & 15.056 & 18,62 & 125.412 & 18,99 \\
\hline Espanha & 70.577 & 12,18 & 8.917 & 11,03 & 79.494 & 2,04 \\
\hline Luxemburgo & 29.530 & 5,09 & 3.580 & 4,43 & 33.110 & 5,01 \\
\hline França & 28.682 & 4,95 & 1.797 & 2,22 & 30.479 & 4,61 \\
\hline Japão & 25.632 & 4,42 & 1.829 & 2,26 & 27.461 & 4,16 \\
\hline Reino Unido & 16.058 & 2,77 & 3.522 & 4,36 & 19.581 & 2,96 \\
\hline México & 15.895 & 2,74 & 3.363 & 4,16 & 19.258 & 2,92 \\
\hline Alemanha & 13.636 & 2,35 & 2.494 & 3,08 & 16.130 & 2,44 \\
\hline Suíça & 10.167 & 1,75 & 4.740 & 5,86 & 14.906 & 2,26 \\
\hline Ilhas Cayman & 11.114 & 1,92 & 3.714 & 4,59 & 14.828 & 2,24 \\
\hline Canadá & 12.340 & 2,13 & 1.556 & 1,92 & 13.896 & 2,10 \\
\hline Bélgica & 3.745 & 0,65 & 4.415 & 5,46 & 8.160 & 1,24 \\
\hline Bermudas & 6.123 & 1,06 & 2.020 & 2,50 & 8.143 & 1,23 \\
\hline Chile & 6.130 & 1,06 & 1.424 & 1,76 & 7.554 & 1,14 \\
\hline Portugal & 6.281 & 1,08 & 1.147 & 1,42 & 7.428 & 1,12 \\
\hline Áustria & 4.424 & 0,76 & 2.544 & 3,15 & 6.968 & 1,05 \\
\hline Itália & 5.518 & 0,95 & 1.136 & 1,40 & 6.654 & 1,01 \\
\hline Ilhas Virgens Britânicas & 4.392 & 0,76 & 1.991 & 2,46 & 6.383 & 0,97 \\
\hline Austrália & 5.263 & 0,91 & 768 & 0,95 & 6.030 & 0,91 \\
\hline Demais países & 31.023 & 5,35 & 8.103 & 10,02 & 39.126 & 5,92 \\
\hline
\end{tabular}

Fonte: Banco Central - Censo de Capitais Estrangeiros no país, 2011.

centros financeiros internacionais gera nas estatísticas bilaterais (BACEN, 2011). Há uma realocação de US $\$ 170,5$ bilhões, originalmente declarados como Holanda, Luxemburgo e Ilhas Cayman para Reino Unido, Alemanha, Espanha, Itália, China, Canadá, Portugal, Austrália, França, Japão, Suíça e Bélgica, entre outros. A Holanda, que aparecia na primeira posição pelo critério de investidor imediato, passa para $10^{\mathrm{a}}$ Tabela 6 - IED - participação no capital, por país do investidor final estoque em 31/12/2010

\begin{tabular}{|c|c|c|}
\hline \multirow{2}{*}{ Países } & \multicolumn{2}{|c|}{ Total } \\
\hline & US\$ milhões & $\%$ \\
\hline Total & 579627 & 100,0 \\
\hline Estados Unidos & 104698 & 18,1 \\
\hline Espanha & 85295 & 14,7 \\
\hline Bélgica & 50374 & 8,7 \\
\hline Brasil & 47841 & 8,3 \\
\hline Reino Unido & 41667 & 7,2 \\
\hline França & 30767 & 5,3 \\
\hline Alemanha & 30308 & 5,2 \\
\hline Japão & 26586 & 4,6 \\
\hline Itália & 17872 & 3,1 \\
\hline México & 15683 & 2,7 \\
\hline Países Baixos (Holanda) & 14385 & 2,5 \\
\hline Canadá & 13849 & 2,4 \\
\hline Luxemburgo & 13733 & 2,4 \\
\hline Suíça & 13060 & 2,3 \\
\hline Bermudas & 9064 & 1,6 \\
\hline China & 7889 & 1,4 \\
\hline Portugal & 7233 & 1,2 \\
\hline Austrália & 6541 & 1,1 \\
\hline Ilhas Cayman & 4812 & 0,8 \\
\hline Ilhas Virgens Britânicas & 3943 & 0,7 \\
\hline Demais países & 34027 & 5,9 \\
\hline
\end{tabular}

posição, enquanto Estados Unidos, Espanha

e Bélgica assumem a $1^{\mathrm{a}}$, a $2^{\mathrm{a}}$ e a $3^{\mathrm{a}}$ posição.

O Brasil é o $4^{\circ}$ país por critério de investidor final. Segundo o BACEN, isso se deve ao fato de empresas não residentes investidoras no País terem, em seu capital, participação de empresas brasileiras (Tabela 6).

O setor de atividade mais beneficiado com o IED - participação no capital é o de serviços $(44,2 \%)$, seguido da indústria $(39,8 \%)$ e da agricultura, pecuária e extrativa mineral (16\%). Nos serviços, o maior estoque refere-se ao setor de serviços financeiros e atividades auxiliares, com $16,9 \%$ do total, seguido de telecomunicaFonte: Banco Central - Censo de Capitais Estrangeiros no país, 2011. 
ções (7\%). Na indústria, o setor de bebidas é o que mais se destaca (9\%) e, na agricultura, pecuária e extrativa mineral, salientam-se a extração de petróleo e gás natural e extração de minerais metálicos, com 8,5\% e 6,1\%, respectivamente.

Quinze anos antes, em 1995, os setores de atividade de destino do IED eram: 66,9\% para a indústria, 30,9\% para serviços e 2,2\% para agricultura, pecuária e extrativa mineral. O aumento significativo da participação desses dois últimos setores no destino do IED reflete o processo de privatização e de "estrangeirização" dos serviços de telecomunicações, do sistema bancário e da extração mineral vivenciado pelo Brasil, bem como a participação crescente de capital estrangeiro no chamado agronegócio.

Parte do IED é dirigida a transações de fusões e aquisições realizadas no Brasil, o que resulta no aumento da concentração do capital nas diversas atividades. No período 2004 a 2010, o capital estrangeiro esteve envolvido em 31,19\% das fusões e aquisições ocorridas. Em 2010, de um total de 726 transações (um recorde desde 1994), 333 foram realizadas por empresas brasileiras no país; 175 por empresa de capital majoritário estrangeiro, que adquiriu de brasileiros, capital de empresa estabelecida no país; 65 por empresa de capital majoritá- Fonte: BACEN. Elaboração própria. rio brasileiro, que adquiriu de estrangeiros, capital de empresa estabelecida no exterior; 35 por empresa de capital majoritário brasileiro, que adquiriu de estrangeiros, capital de empresa estabelecida no Brasil; 108 de empresa de capital majoritário estrangeiro, que adquiriu de estrangeiros, capital de empresa estabelecida no Brasil; e 10 por empresa de capital majoritário estrangeiro, que adquiriu de brasileiros, capital de empresa estabelecida no exterior (KPMG, 2010).

\section{O investimento estrangeiro em carteira e em derivativos}

Em 1991, a Resolução 1.832 do Conselho Monetário Nacional acrescentou à Resolução 1289/87 o Anexo IV, que permitiu que o capital estrangeiro fosse aplicado na Bolsa de Valores e em Fundos ou Carteiras de Investimento o Brasil. Entre esse ano e 2011, o volume líquido do capital estrangeiro em carteira ${ }^{12}$ aumentou em $384,6 \%$. Mas, como esse é um tipo de capital extremamente volátil, mais importante do que esse indicador, é relevante acompanhar o volume da soma das entradas e saída havidas em cada ano, o que pode ser observado no Gráfico 3.

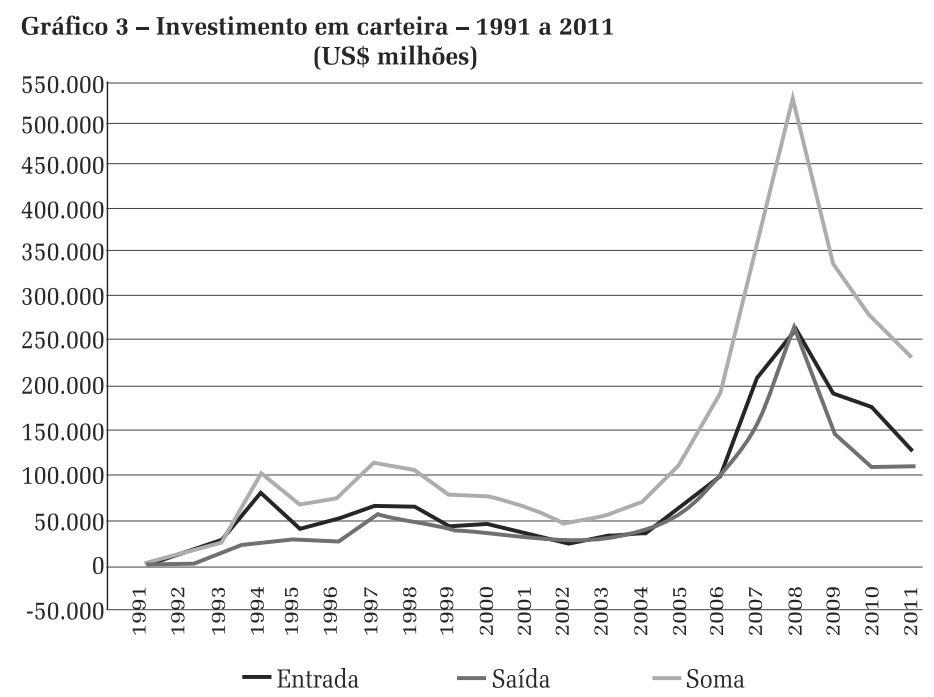

Em 2008, ano bissexto, quando ocorreu o maior volume de dólares referente às entradas e saídas no país, na modalidade de investimento estrangeiro de carteira, houve um movimento diário ${ }^{13}$ de US\$ 2.092,89 milhões. Ainda no Gráfico 3, pode-se acompanhar a volatilidade desse tipo de capital, de modo que, com exceção de alguns anos, o movimento de saída aparece como quase uma sombra do movimento de entrada. $\mathrm{O}$ volume de saída observado em cada ano, muito

\footnotetext{
${ }^{12}$ Definido como o resultado das entradas e saídas de capital estrangeiro em carteira.

${ }^{13}$ Considerando os dias úteis no ano.
} 
próximo ao de entrada, indica que as operações realizadas ocorreram no mercado secundário, tratando-se, portanto, de capital especulativo ou fictício. Do volume de entrada e de saída em 2011, 66,19\% e 70,78\%, respectivamente, foram destinados à compra de ações de companhias brasileiras e 33,81\% e 29,2\%, também respectivamente, a títulos de renda fixa de curto e longo prazo.

Apesar dos saldos entre as entradas e saídas serem pequenos, o montante acumulado de capitais de curto prazo, aplicado em ações e títulos de renda fixa é impressionante. Segundo os dados registrados pelo Banco Central do Brasil, nas estatísticas sobre a Posição Internacional de Investimentos, o estoque dessas aplicações, que caiu de US $\$ 509,6$ bilhões, no final de 2007, para US $\$ 287,5$ bilhões um ano depois, recuperou-se rapidamente para US $\$ 561,8$ bilhões, em 2009 até US\$ 663,8, em 2010 e US\$ 602,9 bilhões, em 2011. A recuperação desse volume de capital especulativo está fortemente associada à política monetária dos países centrais.

O movimento de entrada e saída de derivativos no balanço de pagamentos brasileiro é pouco expressivo, quando comparado ao do investimento estrangeiro direto ou em carteira. Depois de atingir a marca de US\$ 1.289 milhões em 2002, tem registrado valores não superiores a US\$ 250 milhões nos dois últimos anos. Entretanto, em termos de estoque segundo o passivo na Posição Internacional de Investimentos, o montante total de derivativos não sofreu nenhum efeito negativo da crise. Passou de US $\$ 1,8$ bilhão em 2007, para US\$ 2,5 bilhões em 2008, para US $\$ 3,4$ bilhões, US $\$ 3,7$ bilhões e US $\$ 4,8$ bilhões entre 2009 e 2011.

\section{Impactos do aumento do investimento estran- geiro no balanço de pagamentos e no câmbio}

A entrada maciça e continuada de capital estrangeiro no país desde o Plano Real, na forma de investimento direto, investimento em carteira e derivativos, tem custado relativamente caro ao Brasil. O resultado líquido da conta Rendas nas Transações Correntes registra, com raras exceções, uma trajetória ascendente: para um montante de US\$ 8.903 milhões registrado em 1994 pulou para US\$ 47.886 milhões em 2011. Desse último valor, $61,88 \%$ foram rendas derivadas do investimento direto $(92,40 \%$ de lucros e dividendos e 7,60\% de juros de empréstimos intercompanhia), $25,40 \%$ do investimento em carteira $(88,68 \%$ de juros de empréstimos intercompanhias e $11,32 \%$ de juros de títulos de renda fixa) e $12,72 \%$ de outros investimentos. Na eventualidade das repercussões da crise mundial sobre a economia brasileira se aprofundarem, o volume de rendas que saem do país deverá se acelerar, tal como aconteceu em parte de 2008 e 2009, por conta da antecipação de remessas de lucros e dividendos, o que pressionará a moeda.

Mas, mesmo sem considerar essa eventualidade - que, a cada dia que passa, parece se transformar em uma certeza, dada a paralisia do investimento no país e os primeiros sinais de redução do nível de emprego da indústria já aparecendo, o que tem provocado constantes reavaliações para baixo da estimativa de crescimento do PIB, apesar de todos os esforços empreendidos pelo governo no sentido de reduzir as taxas de juros ${ }^{14}$ e de sustentar a demanda via o consumo - é digno de nota o volume de recursos que entram e saem do país diariamente. Em 2011, o movimento do investimento estrangeiro direto e em carteira foi de US\$ 375,07 bilhões (US\$ 1,5 bilhão por dia, sendo 63,53\% em carteira - capital especulativo, como visto anteriormente). Nos primeiros meses de 2012, até maio, esse total foi de US\$ 169,07 bilhões (US\$ 1,6 bilhão por dia), desse total 78,38\% em carteira. Não por outra razão, o governo monitora o mercado de câmbio estritamente, intervindo pesadamente quando a moeda tende a ser valorizar muito ou se depreciar.

${ }^{14}$ De julho de 2011 a agosto de 2012 , a taxa de juros básica (Selic) foi reduzida de $12,50 \%$ para $7,5 \%$ ao ano. Apesar disso, quando comparada com as taxas praticadas em outros países, seu nível ainda é bastante elevado. 
Como visto anteriormente, o volume de investimento estrangeiro que entrou no país nos últimos 17 anos foi surpreendente. O resultado disso é um aumento crescente do passivo da Posição Internacional de Investimentos - PII (apurado pelo valor histórico) ou do Estoque do Investimento Estrangeiro (apurado pelo valor de mercado). Para 2011, o Banco central estimava que o PII fosse de US\$ 1.470.626 milhões. Em caso de aprofundamento da crise, o nível, também surpreendente do nível de reservas (US\$ 372.409 milhões, em 2011), embora confortável, rapidamente irá baixar, denunciando a fragilidade a que está exposta a economia brasileira.

\section{CONSIDERAÇÕES FINAIS}

Há mais de quinze anos, o Brasil tem sido um dos destinos preferenciais do capital internacional. Esse processo acelerou-se com o início da crise de 2007 / 2008 e sua não resolução, a ponto de o país ser, em 2011, o quinto destino do IED no mundo, somente perdendo para os Estados Unidos, China, Bélgica e Hong Kong. A entrada de capitais no país, majoritariamente sob a forma de capital produtivo com participação no capital, aumentou a desnacionalização, anteriormente já acentuada, e a concentração do capital nas diversas atividades econômicas.

No período em análise, o afluxo de capitais estrangeiros tem dois momentos bem demarcados: aquele da segunda fase da privatização das empresas estatais, quando sua participação na compra desses ativos atingiu 53\%, e aquele mais recente, associado ao aumento da liquidez mundial e à relativa taxa de juros praticada no país, em um primeiro momento, e ao crescimento das dificuldades das economias centrais frente ao impacto da crise econômica, em um segundo momento. Entre 1994 a 2011, o fluxo de IED líquido no país elevou-se, fantasticamente, de US\$ 2.150 milhões para US\$ 66.660 milhões.

Para 2010, quando se considera o investidor final, o estoque do IED - participação no capital - origina-se, em primeiro lugar, dos Estados Unidos, estando a Espanha e a Bélgica na $2^{\mathrm{a}}$ e a $3^{\text {a }}$ posição. O setor de atividade mais beneficiado do estoque desse capital é o de serviços $(44,2 \%)$, seguido da indústria $(39,8 \%)$ e da agricultura, pecuária e extrativa mineral (16\%). Em 1995, os setores de atividade de destino do IED eram: $66,9 \%$ para a indústria, $30,9 \%$ para serviços e 2,2\% para agricultura, pecuária e extrativa mineral. O aumento da participação desses dois últimos setores no destino do IED é consequência da privatização e da "estrangeirização" dos serviços de telecomunicações, do sistema bancário e da extração mineral vivenciado pelo Brasil, bem como a participação crescente de capital estrangeiro no chamado agronegócio exportador. Esse capital está intimamente vinculado às fusões e aquisições ocorridas no país nos últimos anos: entre 2004 e 2010, o capital estrangeiro participou de $31,39 \%$ das fusões e aquisições havidas.

Embora em volume o investimento estrangeiro líquido em carteira não tenha a magnitude do produtivo, chama atenção seu forte crescimento (de 384,6\% entre 1991 e 2011). Em 2008, quando ocorreu o maior volume de dólares referente às entradas e saídas no país na modalidade de investimento estrangeiro de carteira, houve um movimento diário ${ }^{15}$ de US $\$ 2.092,89$ milhões. No período em análise, com raras exceções, o movimento de saída aparece como quase uma sombra do movimento de entrada, o que indica que as operações ocorreram no mercado secundário, tratando-se, portanto, de capital especulativo ou fictício. Mas o forte crescimento observado no fluxo é ainda maior quando se analisa estoque: segundo a PII, ele passou de US\$ 151,7 bilhões em 2001, para US\$ 602,9 bilhões em 2011, um pouco abaixo do estoque do IED (US\$ 669,7 bilhões).

A entrada maciça e continuada de capital estrangeiro no país desde o Plano Real tem gerado uma verdadeira sangria, pressionando o resultado líquido da conta Rendas nas Transações Correntes: de 1994 a 2011, ele passou de US\$ ${ }^{15}$ Considerando os dias úteis no ano. 
8.903 milhões para US\$ 47.886 milhões. Aprofundando-se os impactos da crise mundial sobre a economia brasileira, o volume de rendas que saem do país deverá se acelerar, tal como aconteceu em parte de 2008 e 2009, por conta da antecipação de remessas de lucros e dividendos, o que pressionará a moeda. Como visto anteriormente, o volume de investimento estrangeiro que entrou no país nos últimos 17 anos foi surpreendente. O resultado da entrada continuada de capital estrangeiro no Brasil, nos últimos 17 anos, gerou um elevado passivo da Posição Internacional de Investimentos. Em caso de aprofundamento da crise e da saída de parte desse capital, o nível elevado das reservas (US\$ 372.409 milhões, em 2011) não impedirá que sejam expostas as bases frágeis como foram construídas a relação da economia com o capital internacional.

Recebido para publicação em 04 de novembro de 2012

Aceito em 13 de março de 2013
GONTIJO, Cláudio. Why PIGs Can’t Fly. Economistas. Revista do Conselho Federal de Economia. Ano III, No. 7, abril 2012. p. 12-22.

KEYNES, John Maynard. A teoria geral do emprego, do juro e da moeda. 2ed. São Paulo: Nova Cultural, 1985.

KPMG CORPORATE FINANCE. Pesquisa de Fusões \& Aquisições - transações realizadas no Brasil. Vários anos. Disponível em www.kpmg.com.br/publicacoes fas.asp?ft $=5 \& \mathrm{fx}=16$. Acesso em 12 de julho de 2012.

MARQUES, Rosa Maria; NAKATANI, Paulo. O que é capital fictício e sua crise. Col Primeiros Passos. São Paulo: Brasiliense, 2009.

MARX, Karl. O Capital: crítica da economia política. Livro 3, vol. V. 2ed. São Paulo: Nova Cultural, 1986.

UNCTAD - United Conference on Trade and Development. World Investment Report 2012. Disponível em www.unctaddocs.org/files/UNCTAD-WIR2012-Full-en.pdf. Acesso em 11 de julho de 2012.

WORLD BANK. GDP Growth (annual \%). http:// data.worldbank.org/indicator/ny.gdp.mktp.kd.zg. Acesso em 13 de julho de 2012.

\section{REFERÊNCIAS}

BACEN. Banco Central do Brasil. Capitais brasileiros no exterior, 2006. Disponível em www4.bcb.gov.br/rex/cbe/port/ resultadocbe.asp?idpai=cbe. Acesso em 12 de julho de 2012.

Banco Central do Brasil. Capitais brasileiros no exterior, 2011a. Disponível em www4.bcb.gov.br/rex/cbe/port/ cbe2010.asp?idpai =cbedeclant. Acesso em 12 de julho de 2012 .

Banco Central do Brasil. Censo de capitais estrangei-

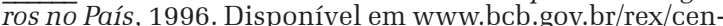
so1995/port/resultado.asp?idpai=CENSO 1995P; Acesso em 10 de julho de 2012.

Banco Central do Brasil. Censo de capitais estrangeiros no país, 2011b. Disponível em www.bcb.gov.br/Rex Censo2010/port/resultados_preliminares. asp?idpai= CENSOCE. Acesso em 10 de julho de 2012.

. Banco Central do Brasil. Série Histórica da Posição Internacional de Investimento, 2012. www.bc.gov.br/ ?SERIEPIIH. Acesso em 19 de julho de 2012.

BIS. Triennial Central Bank Survey. Report on global foreign exchange market activity in 2010. www.bis.org/press/ p060718.htm. Acesso em 13 de julho de 2012.

CITYWIRE. What is 'LTRO' and how does it work? http:// citywire.co.uk/money/what-is-ltro-and-how-does-it-work/ a569758. Acesso em 18 de julho de 2012.

FED. Federal Reserve Bank. Aggregate reserves of depository institutions and the monetary base. www.federalreserve.gov/ releases/h3/current/h3.htm. Acesso em 18 de julho de 2012. 


\section{CRISIS, FICTITIOUS CAPITAL AND THE FLOW OF FOREIGN CAPITAL INTO BRAZIL}

\author{
Rosa Maria Marques \\ Paulo Nakatani
}

This study aims to analyze the impact of recent years capital inflows in the Brazilian economy in the light of the uncommon growth of international fictitious capital and the world economic crisis developpement. Besides highlighting the amount of money involved and its impact on the level of reserves and the exchange rate, it stresses the importance of those figures that fall within the capital and financial accounts in the balance of payments as portfolio investment and derivatives, which sets a high exposure degree of the economy to sudden movements of international capital, especially in the event of a worsening in the crisis. The paper also provides elements about the origins and destination of foreign direct investments made in the country, as well as its importance in privatization, mergers and acquisitions processes.

KEY wORDS: Crisis. Fictitious capital. Foreign capital. De-nationalization. Brazil.

\section{CRISE, CAPITAL FICTIF ET AFFLUENCE DE CAPITAUX ÉTRANGERS AU BRÉSIL}

\author{
Rosa Maria Marques \\ Paulo Nakatani
}

Lobjectif de cette étude est d'analyser, à la lumière de l'énorme croissance du capital fictif et du développement de la crise économique mondiale, l'impact qu'a eu sur l'économie brésilienne l'entrée de capitaux au cours des dernières années. Non seulement cette analyse attire l'attention sur le volume des ressources engagées et de leur impact sur le niveau des réserves et des taux de change, mais elle souligne aussi l'importance des ressources comptabilisées dans le compte capital et finance de la balance des paiements en tant qu'investissements de portefeuille et dérivés. Ceci configure un degré d'exposition élevé de l'économie aux mouvements brusques du capital international surtout en cas d'aggravation de la crise. L'article parle également d'éléments concernant l'origine et la destination des investissements directs effectués dans le pays avec des capitaux étrangers ainsi que de leur importance dans les processus de privatisation, de fusion et d'acquisition.

Mots-clés: Crise. Capital fictif. Capitaux étrangers. Dénationalisation. Brésil.

Rosa Maria Marques - Pós-doutorado em Economia pela Université Pierre Mendès France e pela Universidad de Buenos. Professora do Departamento de Economia e do Programa de Estudos Pós-graduados em Economia Política da Pontifícia Universidade Católica de São Paulo; é líder Grupo de Pesquisa .Políticas para o Desenvolvimento Humano - PDH., desenvolvendo pesquisas na área de políticas sociais, mercado de trabalho, capitalismo contemporâneo e economia brasileira. Suas mais recentes publicações são: A desmedida do capital: notas para uma crítica do subconsumismo (Revista da Sociedade Brasileira de Economia Política, v. 34, 02/2013); Políticas de transferência de renda no Brasil e na Argentina. Revista de Economia Política, v.33, n. 1 (jan-mar. 2013); La crisis mundial y la economía brasileña. Realidad Económica, v. 265, Buenos Aires, 2012).

Paulo Nakatani - Doutor em Economia. Professor do Departamento de Economia da Universidade Federal do Espírito Santo. Membro do Grupo de Pesquisa Estudos Críticos do Desenvolvimento, desenvolvendo pesquisas na área de financeirização, globalização, socialismo e desenvolvimento. Publicações recentes: $L a$ crisis mundial y la economia brasileña. Realidad Económica, v. 265, p. 01-15, 2012; Histórico e os limites da reforma agrária na contemporaneidade brasileira. Serviço Social \& Sociedade, v. 110, p. 213-240, 2012; Notes sur Marx et Keynes a propos de la crise. Critique Économique, v. 13, p. 63-76, 2012; Le Venezuela de la révolution bolivarienne. Changements structurels, planification et transition. Economies et Sociétés (Paris), v. 45, p. 383-396, 2011. 